\title{
A Combined Bilateral Approach to Anterior Communicating Artery Aneurysm
}

\section{Anterior Komünikan Arter Anerrizmasına Kombine Bilateral Yaklaşım}

\author{
Yong-An CHEN ${ }^{1,2}$, Rong-Bo QU³ ${ }^{3}$ Yu-Song BIAN ${ }^{2}$, Wei ZHU², Kun-Peng ZHANG ${ }^{2}$, Qi PANG ${ }^{4}$ \\ ${ }^{1}$ Qilu Hospital, Shandong University, Department of Neurosurgery, Jinan, China \\ ${ }^{2}$ Qingdao University, School of Medicine, Yantai Yuhuangding Hospital, Department of Neurosurgery, Yantai, China \\ ${ }^{3}$ Lanzhou Medical University, Yantai Affiliated Hospital, Department of Neurosurgery, Yantai, Shandong, China \\ ${ }^{4}$ Shandong University, Shandong Provincial Hospital, Department of Neurosurgery, Jinan, China
}

Corresponding Author: Qi PANG / E-mail: liweijing72@163.com

\begin{abstract}
AIM: To discuss the features, feasibility, and safety of a combined bilateral approach in the endovascular treatment of intracranial anterior communicating artery (ACOA) aneurysm.

MATERIAL and METHODS: We performed a retrospective analysis of the clinical data of patients with ACoA aneurysm treated with a combined bilateral approach.

RESULTS: We successfully embolized aneurysms in nine patients with intracranial ACoA aneurysm using a combined bilateral approach. All treated patients had an open ACoA connecting with the bilateral anterior cerebral arteries.

CONCLUSION: Because the ACoA connects the intracranial arteries in both hemispheres, patients with ACoA aneurysm can be endovascularly treated with a combined bilateral approach. Notably, surgeon experience and dexterity play important roles in the success of this procedure.

KEYWORDS: Anterior communicating artery aneurysm, Endovascular techniques, Therapeutic embolization
\end{abstract}

ÖZ

AMAÇ: İntrakraniyal anterior komünikan arter (ACOA) anevrizmasının endovasküler tedavisine kombine bilateral yaklaşımın özellikleri, uygulanabilirliği ve güvenliği üzerinde durmak.

YÖNTEM ve GEREÇLER: Kombine bilateral yaklaşımla tedavi edilen ACoA anevrizmalı hastalarda klinik verilerin retrospektif analizi yapıldı.

BULGULAR: İntrakraniyal ACoA anevrizmalı dokuz hastada kombine bilateral yaklaşım uygulanarak anevrizmalarda başarıyla embolizasyon gerçekleştirildi. Tedavi edilen tüm hastalarda bilateral anterior serebral arterle devamlılık gösteren açık ACoA mevcuttu.

SONUÇ: ACoA her iki hemisferde intrakraniyal arterler arasında bağlantı kurduğundan ACoA anevrizması olan hastalarda kombine bilateral yaklaşımlı endovasküler tedavi yapılmalıdır. Cerrahın deneyimi ve becerileri bu işlemin başarısında önemli rol oynar.

ANAHTAR SÖZCÜKLER: Anterior komünikan arter anevrizması, Endovasküler teknikler, Terapötik embolizasyon

\section{INTRODUCTION}

Anterior communicating artery $(\mathrm{ACOA})$ aneurysms account for $30 \%$ of all intracranial artery aneurysms (10). Due to the complicated structure of the ACoA, hemodynamic change plays an important role in aneurysm pathophysiology $(3,7$, 17). The single-channel technique is always adopted in the endovascular treatment of ACOA aneurysm, but catheterdirected embolization might cause temporary hemodynamic change in the $\mathrm{ACOA}$ or adjoining blood vessels, rendering the aneurysm or its connecting arteries temporarily undetected under angiography, which precludes the completion of embolization (11). In addition, single-channel angiography is not able to obtain a comprehensive understanding of bilateral $A 1$ and $A 2$ structure, and it is unable to ascertain the impact of embolization on blood flow in bilateral A2. This could lead to a mistaken embolization of the opening of A2. Conversely, dualchannel angiography is a good alternative for endovascular embolization because it provides real-time evaluation of blood flow in $\mathrm{A} 1$ and $\mathrm{A} 2$, and interventive measures can be taken according to the intra-operative situation. The dualchannel technique is also necessary to determine if a stent or filled balloon is required to protect A1 and A2. A series of patients with intracranial $A C o A$ aneurysm received treatment using a combined bilateral approach in our center. Here, we discuss the features of a combined bilateral approach, including its feasibility, safety, and efficacy in clinical practice. Our findings provide a reference for the surgical approach and embolization method of complicated ACoA aneurysms.

\section{MATERIAL and METHODS}

From January 2007 to February 2013, 296 patients with ACoA aneurysm received treatment at our cerebrovascular disease center. Inclusion criteria were as follows: 1) ACoA aneurysm identified in digital subtraction angiography (DSA) with 
bilateral anterior cerebral arteries connected to the ACoA. 2) Difficult approach with single lateral approach endovascular therapy for an experienced surgeon. Patients meeting the criteria underwent a combined bilateral approach embolization and accounted for $3 \%$ of all patients with ACoA aneurysm receiving endovascular therapy in this time period. Overall, we included nine patients (four males, five females) with an average age of 61 years (range, 50-81 years). The primary symptom of these nine patients was spontaneous subarachnoid hemorrhage. According to the Hunt-Hess classification, the group included one Grade I case, two Grade II cases, four Grade III cases, and two Grade IV cases. Three cases underwent simple coil embolization, two cases received balloon-assisted embolization, and four cases required stent-assisted embolization. All nine cases were given dense embolization, and Glasgow Outcome Scores (GOS) at discharge included eight cases of Grade 5 and one case of Grade 4. After follow-up of 1-3 years, no aneurysm relapse or stenosis of the aneurysm-loaded arteries was observed.

\section{Endovascular Embolization Therapy}

All patients underwent the DSA investigation under local anesthesia, and the location, size, shape, and relationship between the aneurysm and its artery were ascertained with $3 \mathrm{D}$ reconstruction. During the embolization operation, all patients were under general anesthesia. Heparin was titrated during the procedure to achieve an activated clotting time of 2-2.5 times that of baseline. An intravenous line was established through the bilateral internal jugular vein before heparinization in 2 cases, and bilateral internal jugular venous lines were intra-operatively established after heparinization in 7 cases. Although embolizations could not be performed in routine single lateral angiography through the ipsilateral internal carotid artery, the embolizations were possible with the dual-channel technique. During stent-assisted operation, aspirin (300 mg) was injected at the start of the procedure, and four clopidogrel pills (300 mg each) were crushed and injected into the nasogastric tube during the procedure. Based on 3D-DSA reconstruction, two optimal working locations were ascertained: one clearly revealing the aneurysm-loaded artery, and the other clearly revealing the neck of the aneurysm for coil embolization. At the selected location, DSA was applied to perform the measurement, and the stent was chosen accordingly, with the width ranging from $2.5 \mathrm{~mm}$ to $6 \mathrm{~mm}$, and the length from 10 to $30 \mathrm{~mm}$. The stent length was at least $5 \mathrm{~mm}$ larger than the neck of the aneurysm, and the width was 0.5-1 mm greater than the width of the aneurysm-loaded artery. The stent placement site was ascertained under fluoroscopy, and a microcatheter parallel placement technique was used. Regarding the intra-operative situation, the stent was deployed using pre-release, postrelease, or half-release techniques. Patients were maintained on two anti-platelet agents (75 mg clopidogrel daily and 100 $\mathrm{mg}$ aspirin daily) for 1 month, and aspirin (100 mg/day) for 6 months. For balloon-assisted embolization, the ideal balloon location was identified, the microcatheter was advanced to the appropriate place of the aneurysm cavity (according to the operator's preference, the microcatheter could be placed first), and appropriate placement of balloon could seal off the aneurysm neck from both sides. Balloon filling was carried out slowly and steadily under fluoroscopy and usually lasted no more than $5 \mathrm{~min}$. When the coil was entirely advanced into the aneurysm, the balloon was deflated slowly, and coil motion was observed. When the balloon was completely deflated, angiography was performed to ascertain the stability of the coil before it was released. Again, another appropriately sized coil was chosen to repeat the insertion until the aneurysm was satisfactorily embolized.

\section{RESULTS}

Figure 1A-D shows the hemodynamic evaluation of an intracranial ACOA aneurysm using the dual-channel technique. The cerebral angiography and $3 D$ reconstruction suggested that the left A1 artery was the main aneurysm supply, but the aneurysm was also closely related to the opening of right $A 2$. Pre-operative imaging suggested that the right $A 2$ was supplied by bilateral A1. Embolization was performed through the left channel, and cerebral angiography was taken before the release of the first coil; the right $\mathrm{A} 2$ was radio-transparent. There were two possibilities: 1) microcatheter and coil interference on $A 1$ and $A C o o A$ led to $A 2$ radio-transparency of $A 2$; under this circumstance, the coil could be released and the embolization could continue or 2) the opening of right $A 2$ was mistakenly embolized due to coil interference, and the embolization should be aborted. In order to determine the situation, the coil should be kept intact, and the right channel should be established for angiography. The image suggested the blood supply from right $A 1$ to $A 2$ was good, demonstrating that the opening of right $A 2$ was not affected by the coil. In this situation, the coil should be released, and the embolization should be continued under the angiography through the right channel.

Figure $2 A-D$ shows an $A C o A$ aneurysm before bilateral A1-A2 half-release stent-assisted embolization using a combined bilateral approach. This patient had a complicated ACoA aneurysm. Intra-operative angiography and $3 \mathrm{D}$ reconstruction suggested it was supplied by bilateral $A 1$, and the openings of bilateral A2 were upstream of the aneurysm. The stent advanced from right $A 1$ to right $A 2$ through the right channel, and the microcatheter was placed using a parallel placement technique. The left stent advanced from left A1 to left A2 through the left channel. Bilateral simultaneous stent halfrelease combined with coil remodeling of bilateral $A 1$ and $A 2$ was used to successfully embolize the aneurysm.

Figure $3 A-D$ depicts an ACoA aneurysm that was treated with balloon-assisted embolization where a combined bilateral approach temporarily altered blood flow within Willis' Circle. The aneurysm was mainly supplied by right A1. During the operation, the microcatheter was advanced to the expected location through right channel and part of the coil protruded into the aneurysm-loaded artery during the insertion. The coil was retracted, but the microcatheter remained in the aneurysm. Under right side angiography, 


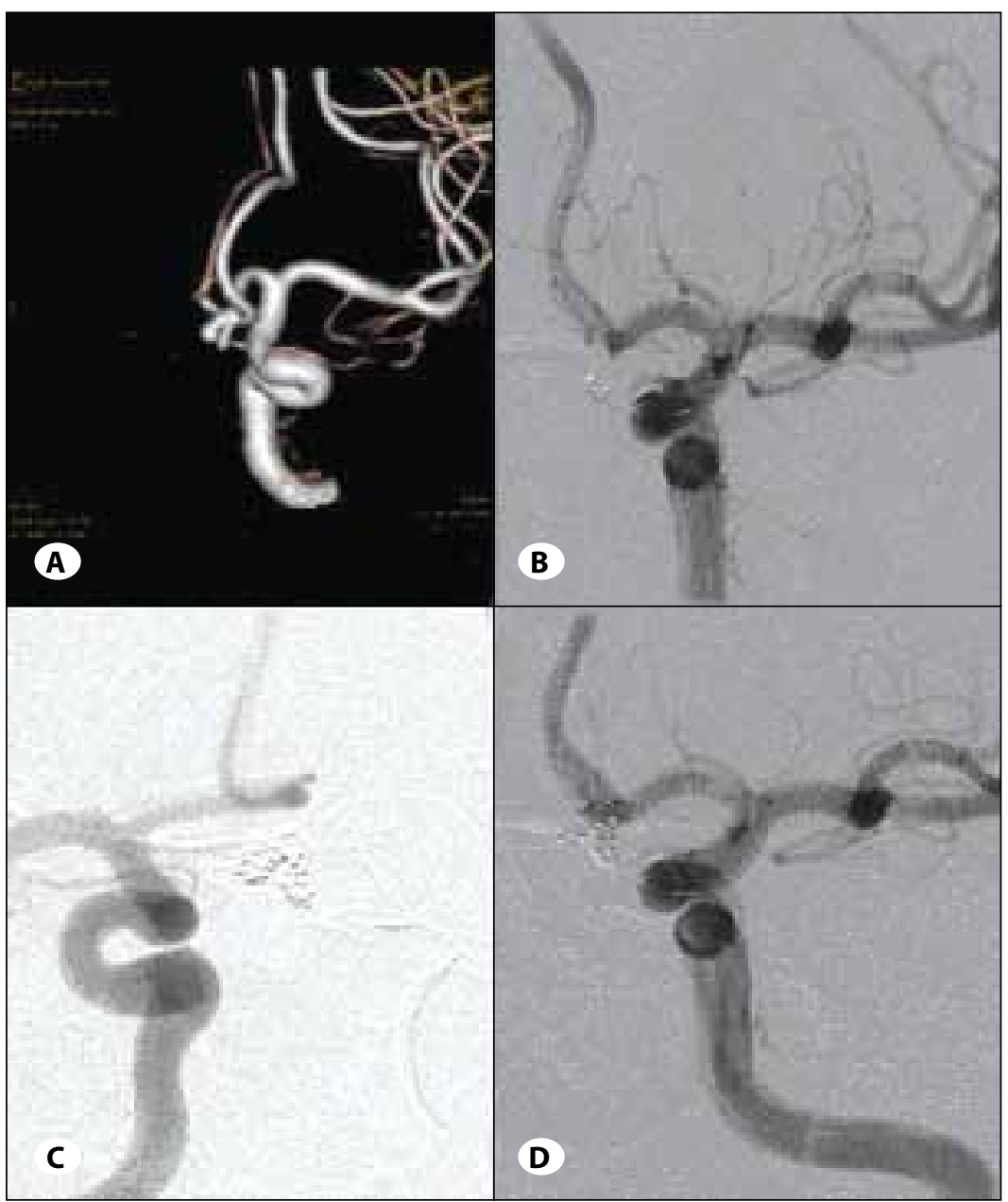

Figure 1: Images of anterior communicating artery aneurysm using simple coil embolization with the help of a dual-channel technique. A) Before embolization, left-channel angiography suggests that left internal carotid artery $\mathrm{A} 1$ supplies anterior communicating aneurysm and bilateral $A 2$. The opening of right $A 2$ is near the aneurysm.

B) During embolization, left-channel angiography suggests radio-transparency of right $A 2$, and the coil was not deployed.

C) Right-channel angiography was performed to identify A2 opening, which appeared normal. The coil was released, and the embolization procedure continued with the assistance of right-channel angiography.

D) Successful aneurysm embolization. the un-embolized aneurysm disappeared, possibly caused by the microcatheter interfering with the hemodynamics in right $\mathrm{A} 1$ and $\mathrm{ACo} A$. If ipsilateral balloon placement was also performed, the bloodstream in the aneurysm would decrease further, leading to disappearance of the aneurysm under angiography. During the operation, the left channel was opened and balloon-assisted embolization was performed. After the balloon advanced from left $A 1$ to right $A 2$ with the balloon unfilled, right side angiography was performed again, and the aneurysm re-appeared under angiography, because the blood supply of A1 to aneurysm was reduced due to the block by balloon catheter of the blood stream of left A1, causing hemodynamic change which resulted in increased blood supply from right $A 1$ to the aneurysm. With balloon advancing to the required location through the left channel, the aneurysm was successfully embolized by a coil through the right channel.

\section{DISCUSSION}

The $A C O A$ is narrow and tortuous and the structure of anterior communicating artery complex is anatomically complicated, making treatment of ACoA aneurysms extremely difficult (1). With the development of endovascular therapy, better embolization materials and improved surgeon dexterity, interventive therapy for some complicated intracranial ACoA aneurysms has become possible $(4-6,8,9,12-16,18-21)$. In our center, nine patients with ACoA aneurysm were successfully embolized, and no complications were observed. Based on our experience, there were three basic circumstances of anterior communicating artery aneurysm that require a combined bilateral approach endovascular embolization:

1) The combined bilateral approach used for intra-operative evaluation in patients in whom A1 supplies the aneurysm and bilateral $A 2$, and contralateral $A 1$ supplies $A 2$ on the same side, as well. The channel ipsilateral to the aneurysmsupplying artery A1 is the embolization channel, and the contralateral channel is used for the real-time evaluation of blood flow in associated arteries to prevent mistaken embolization of the opening of $A 2$, which is near to aneurysm. The purpose of dual-channel angiography is to monitor bilateral A2 blood flow during embolization to determine whether the $A 2$ opening is affected by the coil and to guide coil release during the operation (Figure 1A-D). Under this circumstance, one channel was used for embolization with the microcatheter, and the second was used to view A2 blood 


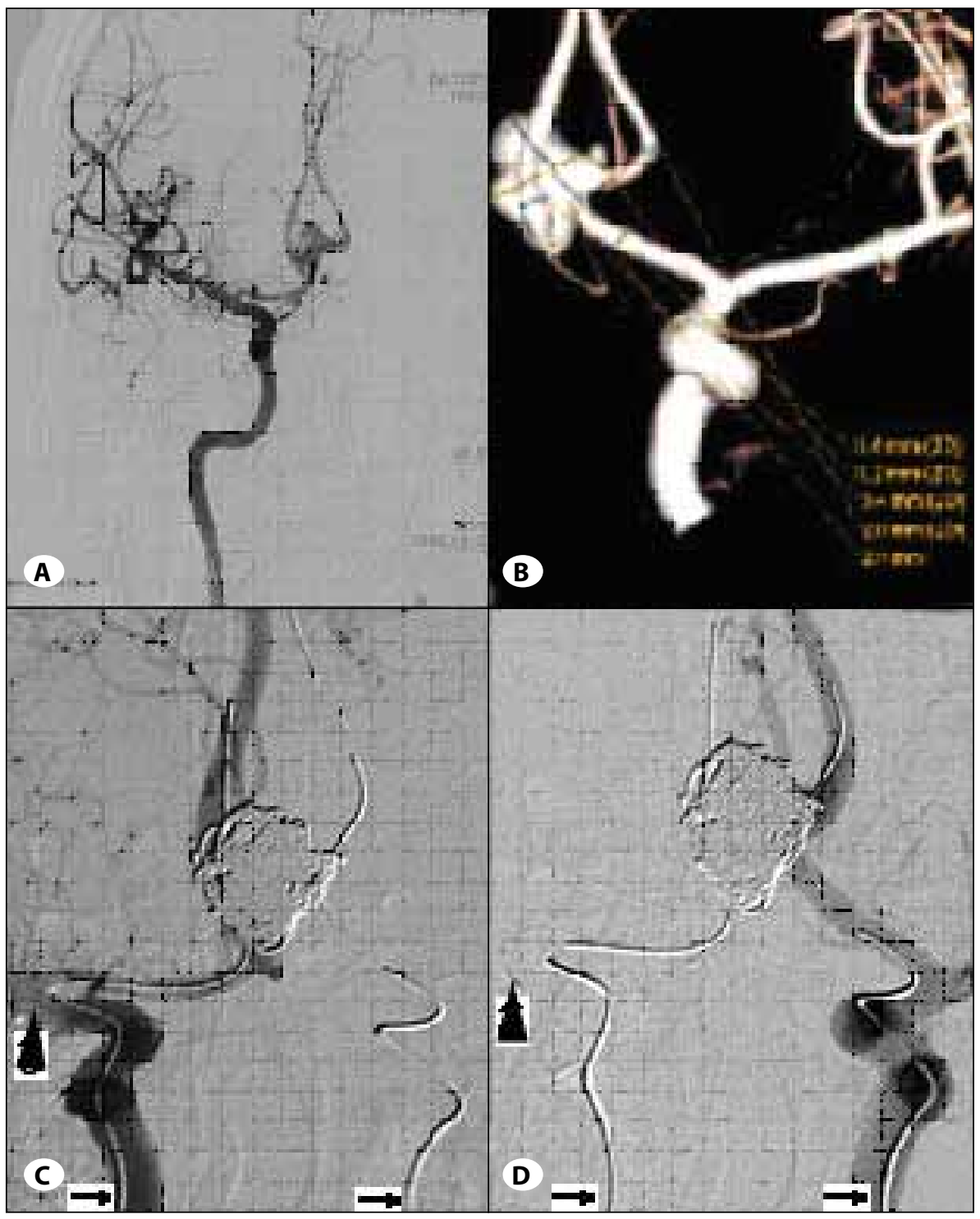

Figure 2: Image of anterior communicating artery aneurysm using stent-assisted coil embolization under the dual-channel technique. A) Right-channel angiography suggests that the right internal carotid artery supplies the anterior communicating artery aneurysm and bilateral A2. The opening of bilateral $\mathrm{A} 2$ is upstream of the aneurysm. B) Left-channel angiography 3-D reconstruction suggests that the left internal carotid artery A1 supplies the anterior communicating artery aneurysm and bilateral A2. Opening of bilateral $A 2$ is upstream of the aneurysm, and the diameters of $A 1$ and $A 2$ and aneurysm size were measured.

C) Right-channel angiography suggests that both stents advanced to the expected sites through bilateral A1-A2, and the aneurysm was successfully embolized with the coil. D) Left-channel angiography suggests both stents advanced to the expected sites through bilateral A1-A2, resembling, and the aneurysm was successfully embolized with the coil. Note microcatheter (arrowheads) and guide wire (small arrows).

flow. If a double-catheter is used, it should be advanced through the embolization channel to ensure that blood flow in the monitoring channel is not disturbed during the operation.

2) The combined bilateral approach used as the surgical approach in patients in whom bilateral $A 1$ and $A 2$ are eroded by the aneurysm and thus require extra protection during the procedure. Therefore, the placement, release, or filling of the stent or balloon must be simultaneous (Figure 2A-D). This situation is often observed in giant ACoA aneurysms, which involve bilateral $A 1$ and $A 2$ and require bilateral stent or balloon-assisted treatment. As for bilateral stentassisted embolization, the stents must be simultaneously half-released or post-released to prevent stent collapse and achieve ideal dense embolization. Similarly, to achieve dense embolization and protect bilateral A2 during balloon-assisted embolization, bilateral balloon filling needs to be performed simultaneously. Bilateral simultaneous stent release or balloon filling must be performed with the help of dualchannel technique. A combined bilateral approach is also required during embolization operation to fully evaluate the impact of the stent or balloon on bilateral A1 and A2 and the embolization status of the target aneurysm.

3) The combined bilateral approach used for temporary blood flow interference in patients in whom the bilateral A1s supply the aneurysm equally. The dual-channel technique can temporarily alter local blood flow in Willis' Circle and enable aneurysm visualization under angiography if necessary (Figure 3A-D). Under this circumstance, if blood flow is altered by the microcatheter, the blood supply from ipsilateral A1 to the aneurysm will decrease and the contralateral flow will increase, leading to the disappearance of ipsilateral aneurysm under angiography. At this time, contralateral bloodstream should change to increase the ipsilateral blood 


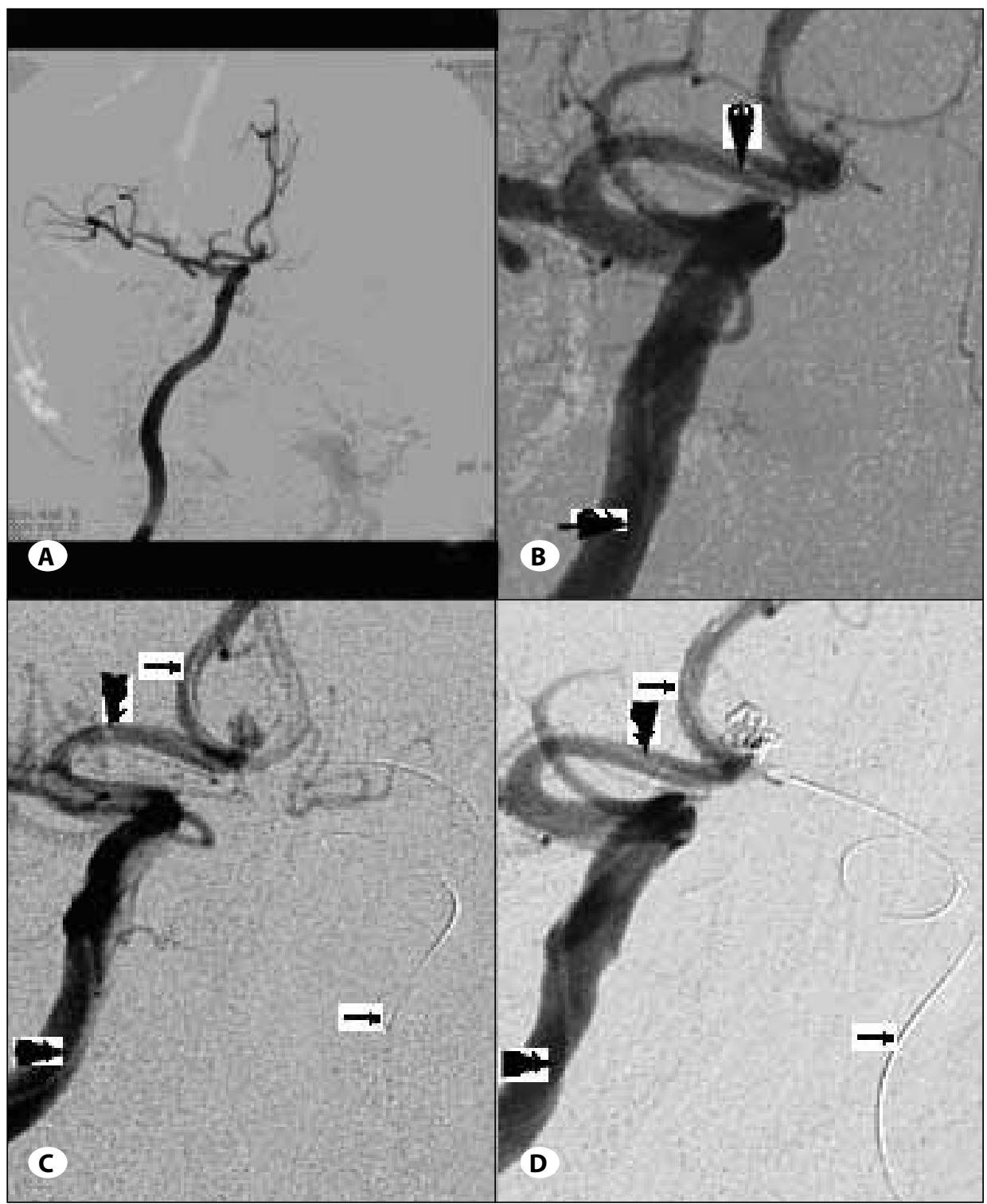

Figure 3: Anterior communicating aneurysm treated with a balloonassisted coil with the help of a dual-channel technique.

A) Right-channel angiography suggests that the right internal carotid artery $\mathrm{A} 1$ supplies the anterior communicating artery aneurysm and bilateral A2.

B) When the microcatheter advanced to expected position through the right channel, the aneurysm and the left A2 disappear, suggesting that both are supplied by the left $\mathrm{A} 1$.

C) The microcatheter in the right channel remains in the aneurysm, and the balloon advances from left $A 1$ to right $A 2$ through the left channel. The balloon remains unfilled, and the aneurysm and left A2 re-appear on right-channel angiography.

D) With the help of the leftchannel balloon, the aneurysm was successfully embolized by advancing the coil through the right channel.

Note microcatheter (arrowheads) and balloon transport system (small arrows). supply to the aneurysm, which will re-appear and allow the surgeon to complete the embolization. Externally pressing on the carotid artery can also temporarily alter the blood flow, but this method is transient and might affect the surgical approach. In the above-mentioned (1) and (3) scenarios, hemodynamic changes caused by vascular spasm due to operation procedure should be strictly avoided. During angiography, evaluation of the status and blood flow of the ACoA and bilateral $A 1$ and A2 is critical. Surgeon dexterity and technique also play important roles in guaranteeing the success of the operation. In patients who can receive dual-channel stent-plasty or dual-channel balloon-assisted embolization, the "waffle cone" technique can also be applied. However, dual-channel stent-plasty or balloon-assisted embolization is superior to the "waffle cone" technique regarding embolization density and protection of aneurysmadjacent vessels. During a combined bilateral approach stent release, the jailing technique for coiling is usually preferred to navigating across both stent walls. Doing so likely reduces the incidence of stent distortion, damage, and movement. As for double-stent placement to protect bilateral A1 and A2 using dual-channel technique, $\mathrm{X}$ placement could be adopted. For giant aneurysm embolization using the dual-channel technique, the one-and-a-half round micro-catheterization technique for microcatheter remodeling is usually adopted. Continuous fluid infusion should be maintained in both channels when using dual-channel technique to prevent blood clot formation. Although the three circumstances mentioned above are rare in ACoA aneurysm embolization (about 3\% in our center), they are difficult to manage. Therefore, we propose that that employing the dual-channel technique is a good option for embolization therapy.

All patients in this study were successfully embolized, and no operation-related complications were observed during 
the post-operative follow-up of 1-3 years. This technique is a pioneering exploration of endovascular therapy for ACoA aneurysm. However, the sample size was small, and post-operative hemodynamic changes and long-term complications should be further investigated.

\section{CONCLUSION}

Despite the limitations, our study demonstrates that patients with ACoA aneurysm can be treated endovascularly with a combined bilateral approach.

\section{REFERENCES}

1. Albuquerque FC, Gonzalez LF, Hu YC, Newman CB, McDougall CG: Transcirculation endovascular treatment of complex cerebral aneurysms: Technical considerations and preliminary results. Neurosurgery 68: 820-830, 2011

2. Amenta PS, Dalyai RT, Kung D, Toporowski A, Chandela S, Hasan D, Gonzalez LF, Dumont AS, Tjoumakaris SI, Rosenwasser RH, Maltenfort MG, Jabbour PM: Stent-assisted coiling of wide-necked aneurysms in the setting of acute subarachnoid hemorrhage: Experience in 65 patients. Neurosurgery 70: 1415-1429, 2012

3. Cebral JR, Sheridan M, Putman CM: Hemodynamics and bleb formation in intracranial aneurysms. AJNR Am J Neuroradiol 31: 304-310, 2010

4. Galal A, Bahrassa F, Dalfino JC, Boulos AS: Stent-assisted treatment of unruptured and ruptured intracranial aneurysms: Clinical and angiographic outcome. Br J Neurosurg 27(5):607616,2013

5. Goyal S, Kumar S, Sharma R, Husain S: Unusual thromboembolic complication during an anterior communicating artery aneurysm coiling. J Neurointervent Surg 3: 352-354, 2011

6. Gu DQ, Zhang X, Luo B, Long XA, Duan CZ: The effect of Neuroform stent-assisted coil embolization of wide-necked intracranial aneurysms and clinical factors on progressive aneurysm occlusion on angiographic follow-up. J Clin Neurosci 20: 244-247, 2013

7. Hassen T, Hassen AA, Ahmed YM: Influence of parent vessel dominancy on fluid dynamics of anterior communicating artery aneurysms. Acta Neurochir (Wien) 153: 305-310, 2011

8. Hong B, Patel NV, Gounis MJ, DeLeo MJ 3rd, Linfante I, Wojak JC, Wakhloo AK: Semi-jailing technique for coil embolization of complex, wide-necked intracranial aneurysms. Neurosurgery 65: 1131-1139, 2009

9. Kim BM, Park SI, Kim DJ, Kim DI, Suh SH, Kwon TH, Choi HS, Won YS: Endovascular coil embolization of aneurysms with a branch incorporation into the sac. AJNR Am J Neuroradiol 31: 145-151, 2010

10. Krasny A, Nensa F, Sandalcioglu IE, Göricke SL, Wanke I, Gramsch C, Sirin S, Oezkan N, Sure U, Schlamann M: Association of aneurysms and variation of the A1 segment. J Neurointerv Surg 6(3):178-183, 2014
11. Kwon SC, Park JB, Shin SH, Sim HB, Lyo IU, Kim Y: The efficacy of simultaneous bilateral internal carotid angiography during coil embolization for anterior communicating artery aneurysms. J Korean Neurosurg Soc 49: 257-261, 2011

12. Lazzaro MA, Zaidat OO: X-configuration intersecting enterprise stents for vascular remodeling and assisted coil embolization of a wide neck anterior communicating artery aneurysm. J Neurointervent Surg 3: 348-351, 2011

13. Lee JY, Seo JH, Cho YD, Kang HS, Han MH: Endovascular treatment of wide-neck intracranial aneurysms using a microcatheter protective technique: Results and outcomes in 75 aneurysms. AJNR Am J Neuroradiol 32: 917-922, 2011

14. Liu W, Kung DK, Policeni B, Rossen JD, Jabbour PM, Hasan DM: Stent-assisted coil embolization of complex widenecked bifurcation cerebral aneurysms using the "waffle cone" technique, A review of ten consecutive cases. Interv Neuroradiol 18: 20-28, 2012

15. Mahmoud M: Rescue stenting in endovascular treatment of acutely ruptured cerebral aneurysms. Interv Neuroradiol 19: 21-26, 2013

16. Miyachi S, Matsubara N, Izumi T, Asai T, Yamanouchi T, Ota K, Oda K, Wakabayashi T: The 'one and a half round microcatheterization technique' for stent-assisted coil embolization of intracranial aneurysm: Technical case series. J Neurointerv Surg 6(5):357-362, 2014

17. Omodaka $S$, Sugiyama $S$, Inoue $T$, Funamoto $K$, Fujimura M, Shimizu H, Hayase T, Takahashi A, Tominaga T: Local hemodynamics at the rupture point of cerebral aneurysms determined by computational fluid dynamics analysis. Cerebrovasc Dis 34: 121-129, 2012

18. Saatci I, Geyik S, Yavuz K, Cekirge S:X-configured stent-assisted coiling in the endovascular treatment of complex anterior communicating artery aneurysms: A novel reconstructive technique. AJNR Am J Neuroradiol 32: E113-E117, 2011

19. Shima H, Nomura M, Muramatsu N, Sugihara T, Fukui I, Kitamura Y, Hamada J: Embolization of a wide-necked basilar bifurcation aneurysm by double-balloon remodeling using HyperForm compliant balloon catheters. J Clin Neurosci 16: 560-562, 2009

20. van den Bergh WM, Kerr RS, Algra A, Rinkel GJ, Molyneux AJ; International Subarachnoid Aneurysm Trial (ISAT) Collaborative Group: Effect of antiplatelet therapy for endovascular coiling in aneurysmal subarachnoid hemorrhage. Stroke 40:1969-1972, 2009

21. Yavuz K, Geyik S, Cekirge S, Saatci I: Double stent-assisted coil embolization treatment for bifurcation aneurysms: Immediate treatment results and long-term angiographic outcome. AJNR Am J Neuroradiol 34(9):1778-1784, 2013 